\title{
Management Information System and Decision-Making
}

\author{
Afërdıta Berisha - Shaqiri \\ Assistant Professor, Ph.D. Department of Management \&Informatics, \\ Faculty of Economics, University of Prishtina, Kosova
}

\section{Doi:10.5901/ajis.2014.v3n2p19}

\begin{abstract}
Management Information System is flow-processing procedures based on computer data, and integrated with other procedures in order to provide information in a timely and effective manner to support decision-making and other management functions. This finding is also present when we consider that the number of contemporary business data and information exponential grow, and efficient business decision-making is possible only if the necessary information is fast, accurate and qualitative and managed by adequate staff but for the most cases not appropriate efficiency is the result of a lack of good management information systems. The rapid development of information technology coupled with the development of telecommunications technology has streamlined every area of life and human activity. Through good organization of this technology to achieve quality decision making at all levels of management from the top level to the lowest. Information technology in organizing the best and optimal database offers great opportunities for a quick and qualitative manipulation to raise the quality of preparation of decisions.
\end{abstract}

Keywords: Management Information System, decision making, organization, database etc.

\section{Introduction}

Information system is an integrated set of components for collecting, storing and processing data and for delivering information, cards, and digital products. Business firms and Other Organizations rely on information systems to carry out and manage their operations, Interact with their customers and suppliers, and compete in the marketplace. According to (encyclopedia Britannica http://www.britannica.com/EBchecked/topic/287895/information-system) Information system is dynamic area or field monitors changes, perhaps the most important driving force induced by the development of computers. It is a system that works and has to do with the information. The main function of information is to avoid uncertainty and the unknown circumstances creating a solid basis for qualitative decision making in the management and leadership. By Mustafa Muhamet (1995), computer system processor often defined as inputs to outputs or information. Information system is defined as a set of related elements with attributes that enable their electronic data processing.

Computers are being used in all areas it is especially expressed mostly in business. Those who learn to use this powerful tool to gain competitive advantage and provide information that you needed them for careers, successful business, regardless of the profit which field are oriented in finance, marketing, management or in any other field business, and for those who do not confronted with this powerful tool will be away from the future.

System information technology we study how to achieve hardware and programming software combine to build an information system for the business professional. Often people mistakenly think that Information System software is mysterious, complex, and very difficult to understand, this unfortunately is the wrong idea, but management information system is very interesting, logical, essential and very important for successful business and adoption the trailer would be a more reasonable punishment for each.

Information system has to do with the critical functioning of enterprises, institutes and modern businesses. Businesses use information system technology to gain competitive advantage against their rivals. In fact many basic business processes are set to increase output, productivity through the use of information systems.

According to James O.Hicks,Jr (2003), in most cases viewed as system information system consisting of people, equipment and procedures to collect, arrange, analyzed, assessed and disseminated timely information to decision receiver or as a formalized computer system that can collect, feed, process, and report data from various sources to provide the necessary information for management decision-making processes 


\section{Management Information System and Its Tasks}

Information system is entirely related elements among themselves which function together with the purpose of collecting, processing and saving of information distribution.

Author James O. Hicks (2003) defines information system as formalized computer system that collects, stores, processes and reports data from various sources to provide information needed to manage the process of making decisions

J.W. Wilkinson,(n.d) talking about computer operating systems mentioned five tasks or activities: data collection; data processing; data management; control and security of data and information generation.

Through these activities, data from various sources through a process called data processing turn into useful information for the user. Management information systems comprise the physical components of the trailer: hardware, software, databases, procedures and personnel.

By James O.Hicks,Jr (2003) computing system is formalized system where collected and sorted out by several processes, reports, data from various sources to provide the necessary information and important to obtain important management decisions. Not all information systems are organized and formalized such as information from unofficial sources other. Information system should be based on the computer data, often collected and stored information manually through processing, although manual information system has become - much less relevant

The purpose of the system is processing information, the saving and transmitting appropriate information in place, and better information system is the one who performs this function with much less expense. Fig.1. by James O.Hicks,Jr (2003) reflects computer system in six parts: inputs, processes, data files, outputs, personnel and hardware part. All systems including computer systems and computer systems consist of inputs, processes and outputs.

The process of transforming inputs into outputs regards information management (management information). Processes can be subdivided into computer programs and procedures, computer programs executed from the computer hardware and procedures executed by humans.

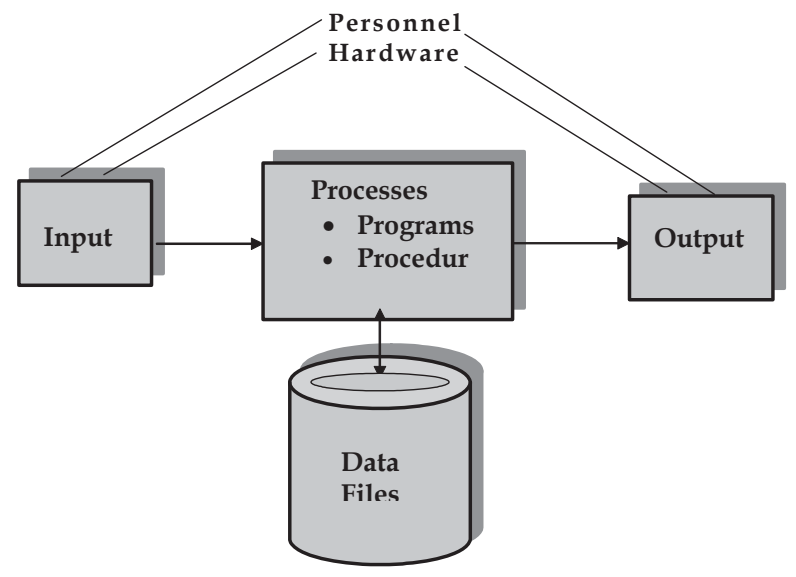

Fig. 1. Introduction to computer system

Before the 1980s the information system is usually classified as a system for data processing or computing system governing (MIS). System data processing was oriented toward conquest, processing, booking (storage) data, while MIS (Management Information System) is directed towards utilization of data to create information governance.

According to Kukaj Ibrahim (2005) computer system helps decision makers in two ways:

a) Assist managers in the decision-making process by providing the necessary information.

b) information system in some cases may even take decisions independently in situations that are repeated when the deployment process does not change, ie in this case differ only incoming variables. By James O.Hicks,Jr (2003) today, the term generally refers to the system that provides periodic information on events common and predictable business. This system creates input information regarding normal business activities for middle level managers and top that (top managers). They also called other management report systems. Impact of 
new technology and new information on the destiny of people is not only in carrying out physical but also intellectual works. According to Ramosaj Berim (1993) the main functions that make up the essence of management as a process in contemporary organization are: planning, organizing, staffing, leading and controlling.

Since managers are responsible for setting goals, they have to make decisions that enable their achievement, and those decisions relating to activities as following:

- Preparation of strategic goals;

- Manage the implementation of strategic decisions;

- The organization of tasks;

- Definition of tasks and resources associated with the appearance of their use;

- Coordination and supervision of employees and managers;

- Detection and correction of problems if they occur.

Provide timely and relevant information needed regarding the performance of these activities is of particular importance to managers in each of the mentioned levels of management. Only thanks to these information manager can take quality decisions

V. Sriča (n.d) mentions three levels of government and that the operational, tactical and strategic framework where tasks are performed governing system of planning and control at all levels with the help of information system.

\section{Support Management Information System in Decision Making}

By James Reason (1990) every decision-making process produces a final choice that may or may not prompt action. Decisions vary depending on the structure, which provided for making those decisions. Modern information technologies offer new solutions for businesses, companies or other scientific institutions, which create new work surroundings which is based on computer communication between people. This differs express surroundings working people, so that enables greater flexibility, easier solutions to business problems, greater creativity, better interpersonal cooperation etc. Well presented solutions that have an impact on people's destiny, not only in performing physical but also intellectual works. Doya, Kenji; Michael N Shadlen (2012) says Most decisions are followed by some form of cost-benefit analysis, people try to maximize benefits while minimizing costs by Schacter, Gilbert, Wegner (2011).

According to Mustafa Muhamet (1995) management information system provides a support for making decisions based on methods and systematic analysis. Relying on this are created with the software who tested alternatives preparatory stage of the decision making process. These systems are known as decision support systems (DSS). A decision support system (DSS) is a computer program application that analyzes business data and presents it so that users can make business decisions more easily. It is an "informational application" (to distinguish it from an "operational application" that collects the data in the course of normal business operation). By Searchcio (http://searchcio.techtarget.com/definition/decision-support-system) typical information that a decision support application might gather and present would be:

- Comparative sales figures between one week and the next

- Projected revenue figures based on new product sales assumptions

- The consequences of different decision alternatives, given past experience in a context that is described

Decision support systems (DSS) on the other hand, are characterized by flexible implementation in the database in a variety of output formats and flexible collection of deployment models.

From such components required more support manager in the decision making process, rather than trying to find solutions and take decisions instead of users.

These systems have been shown to eliminate the shortcomings of management information system and enterprise duly held on as they have gained experience with system management information. The term placements mostly means the process of selecting one of two or more alternative stock in any given situation which will be undertaken in order to achieve any goal in any near future or distant. Decision support systems are presented in the 70's, as generators of new computing solutions for management support.

Starting points of decision support systems are:

- Computer support given to the case of decision making when dealing with structural problems;

- Connect the data models and decisions, efficient computing elections;

- To provide computer support manager. 
Following are the important steps of the decision making process according to tutorialspoint.com Each step may be supported by different tools and techniques

Fig. 2. Steps of decision making process.

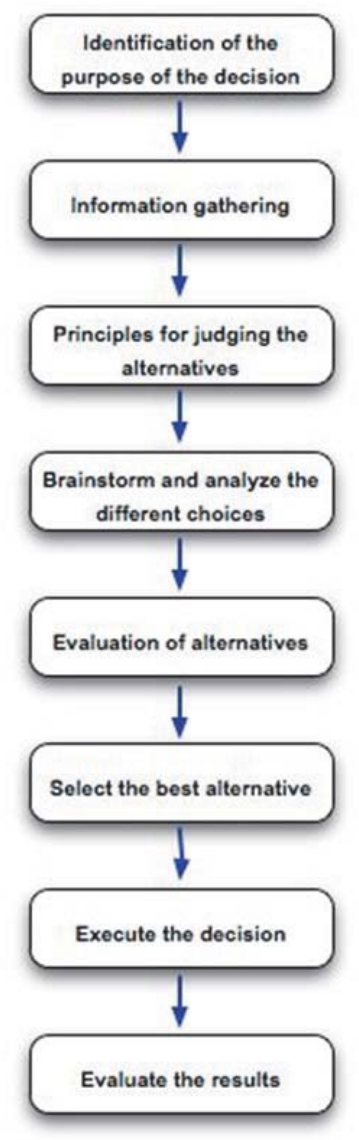

Research phase of the decision-making process includes activities identifying problems associated with reviewing the circumstances of the conditions for making decisions. Analysis and placement cannot be identified until the problem is formulated and therefore not research phase consists of search and research environment for internal and external circumstances which lead to the identification of an opportunity or a problem.

Following the research phase, which results in the recognition of the problem or opportunity, the design phase, involves inventing, developing and analyzing possible directions stock. Support for the design phase should provide iterative procedure when reviewing alternatives.

Decision support system is an information system based on the computer that regulates manipulates and demonstrates the necessary information to make decisions. The role of the computer here is not to replace but to assist the recipient in the decision making process decisions. These systems represent the latest technology and more complex, which enables managers to ask questions and get answers to questions posed and enters the database related to their needs for information and are therefore particularly useful to solve recurring problems.

\section{Summary}

When it comes to making decisions, one should always weigh the positive and negative business consequences and should favor the positive outcomes. This avoids the possible losses to the organization and keeps the company running 
with a sustained growth. Sometimes, avoiding decision making seems easier, especially, when you get into a lot of confrontation after making the tough decision. But, making the decisions and accepting its consequences is the only way to stay in control of your corporate life and time.

Resources are key force multipliers of postindustrial information society and therefore the creation of a knowledge management information system will create good advantage in increasing the efficiency and competitiveness in comparison with the previous centralized systems where communication between subsystems has been more difficult i.e. condition fundamental to the existence and development of enterprises is computerization and better organization of database, structuring the database for research activities and organization of database management needs.

This finding is also present when we consider that the number of contemporary business data and information exponential grow, and efficient business decision-making is possible only if the necessary information be fast, accurate and qualitative and managed by adequate staff for the most cases not appropriate efficiency is the result of a lack of good management information systems.

Basic condition for success is that the development strategy and business plan as the basis for building Information System. This is connected with the great opportunity created by the development of information technology in harmonizing procedures sim-term plan and business plan. Developments in the field of hardware and software support System then proecsin information in decision making (DSS) as a necessary and effective tool for decision makers and create new opportunities for a lot of things successful management when knowledge based on SIM contemporary becomes the main factor of economic development based on the knowledge economy and digital economy.

\section{References}

Doya, Kenji; Michael N Shadlen (2012). "Decision Making". Current Opinion in Neurobiology 22 (6): 911-913. doi:10.1016 lj.conb.2012.10.003

J.W.Wilkinson: Accounting and Information System

James O.Hicks,Jr - Management Information System(Third edition , Virginia Polytechnic Institute and State University), 2003

James Reason (1990). Human Error. Ashgate. ISBN 1-84014-104-2.

Kukaj Ibrahim, Teoria dhe metodat e vendosjes, Prishtinë, 2005.

Mustafa Muhamet - Kibernetike dhe hyrje në informatikë, Prishtine, 1995

Ramosaj Berim, Bazat e Menaxhmentit, Prishtine, 1993

Schacter, Gilbert, Wegner (2011). Psychology. Worth. p. 369.

Internet

http://searchcio.techtarget.com/definition/decision-support-system

http://www.tutorialspoint.com/management_concepts/decision_making_process.htm

http://www.britannica.com/EBchecked/topic/287895/information-system 
